\title{
Gestión de territorios patrimoniales en el siglo XXI. Un análisis comparativo entre modelos chilenos
}

\author{
Cinthia Giménez Arce | Universidad Privada de Santa Cruz de la Sierra (UPSA), \\ Bolivia
}

URL de la contribución <www.iaph.es/revistaph/index.php/revistaph/article/view/4752>

\section{RESUMEN}

El concepto de patrimonio cultural ha ido evolucionando en las últimas décadas, ampliándose con una mirada más integral, territorial e inclusiva. Nos planteamos como objetivo de este artículo estudiar modelos de gestión de patrimonio cultural en el territorio, basados en el trabajo de campo realizado, y contrastarlos con lineamientos teóricos previamente definidos. El artículo se estructura en tres partes: en primer lugar abordamos las reflexiones teóricas que nos han llevado a esquematizar la evolución del concepto del patrimonio cultural y las aristas más representativas que podemos evidenciar en lo que transcurre del siglo XXI. En segundo lugar, nos centramos en el análisis de casos, realizando una descripción de los dos seleccionados para el estudio, profundizando en la contextualización general, el reconocimiento de los valores patrimoniales asociados y por último el modelo de gestión que se han venido implementando. Nos referimos a las iglesias de Chiloé, en el sur del país, inscritas en la Lista del Patrimonio Mundial de la Humanidad, y la denominada Ruta de las Misiones, en el norte del territorio chileno, que se encuentra dentro de la lista indicativa de la Unesco. En la última parte se contrasta el modelo teórico con la propia gestión de estos dos casos y el aporte que pueden llegar a tener en el planteamiento de políticas públicas para la conservación del patrimonio cultural desde el territorio.

\section{Palabras clave}

Archipiélago de Chiloé (Chile) | Arica | Comunidades | Conservación (Patrimonio) | Desarrollo local | Gestión integral | Iglesias | Modelos | Paisaje cultural | Parinacota | Participación ciudadana | Sostenibilidad | Territorio | 


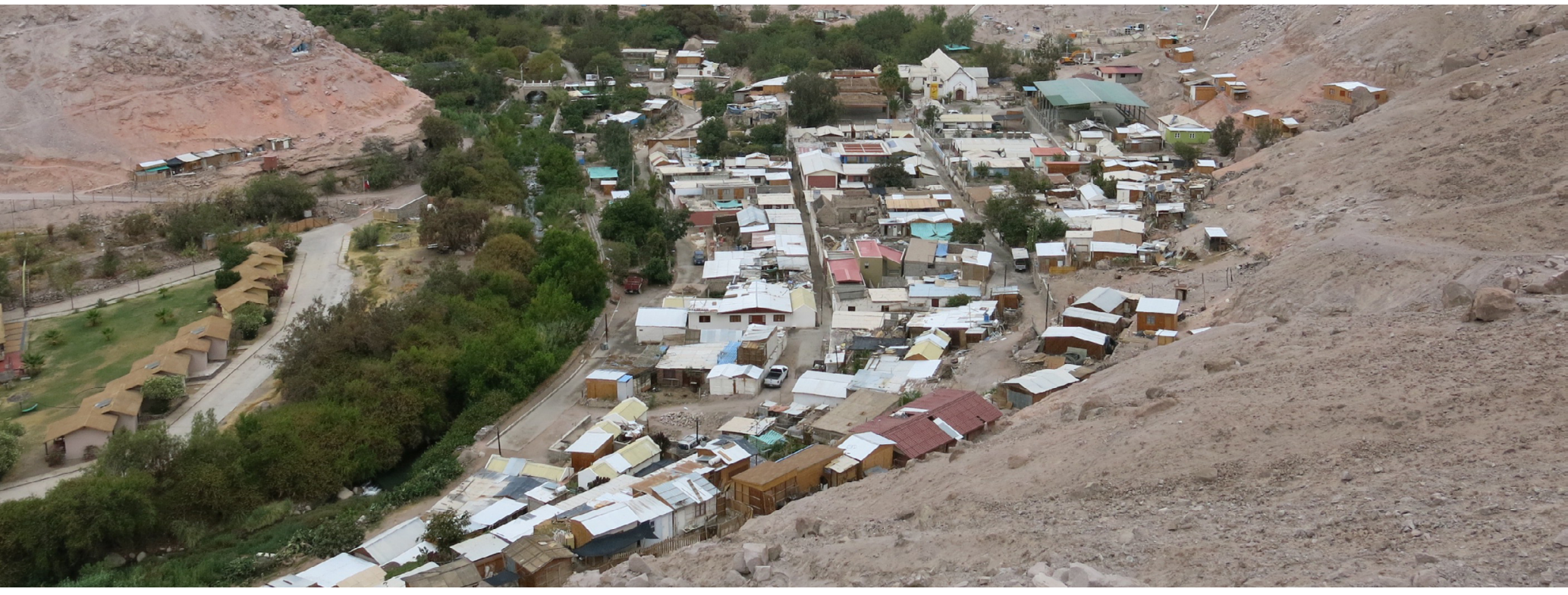

\section{Management of heritage territories in the 21st century. A comparative analysis between Chilean models}

\section{ABSTRACT}

The concept of cultural heritage has been evolving in the last decades, expanding with a more comprehensive, territorial and inclusive perspective. Thus, the objective of this article is to study models of cultural heritage management in a territory determined in the field work and with contrast in previously defined theoretical guidelines. Therefore, for better understanding it is structured in three sections. First, we approach the theoretical reflections that allow us to outline the evolution of cultural heritage and its most representative edges that we can see in the history of the 21st century. Secondly, we focus on the analysis of cases, making a description of each of the two case studies, focusing more on the general context, the recognition of the associated heritage values and, finally the management model that has been implemented. We refer to the churches of Chiloé in the south of the country, which belong to the representative list of the World Heritage Sites as well as the Route of the Missions in the north of the Chilean territory, which is found in the indicative list of the Unesco. Furthermore, the theoretical model contrasts with the model management and the contribution they may have in the approach of public policies for the conservation of cultural heritage from the territory.

\section{Key words}

Archipiélago de Chiloé (Chile) | Arica | Communities | Conservation (Cultural Heritage) | Local development | Integral management | Churches | Models | Cultural landscape | Parinacota | Citizen participation | Sustainability | Territory |

Cómo citar: Giménez Arce, C. (2021) Gestión de territorios patrimoniales en el siglo XXI. Un análisis comparativo entre modelos chilenos. revista PH, n. 103 , pp. 60-79 Disponible en: www.iaph.es/revistaph/index.php/revistaph/article/view/4752 DOI 10.33349/2021.103.4752

Enviado: 31/07/2020 | Aceptado: 06/04/2021 | Publicado: 10/06/2021 


\section{INTRODUCCIÓN}

Durante las últimas décadas los conceptos relacionados con el patrimonio cultural han ido evolucionando y la concepción del mismo se ha ido ampliando, con una visión más integral dentro del desarrollo de las regiones y los países. La idea de la preservación y conservación de los elementos aislados, que generalmente vienen definidos por posturas de expertos foráneos sin tener en cuenta en la mayoría de los casos la valoración local y de contexto, es, entre otras, una postura que ha sido totalmente cuestionada en lo que transcurre de este siglo XXI. Con la ampliación de esta mirada se complejizan los procesos, se amplían los actores y se incluyen, de manera integral, los territorios, con todos sus valores, y la voz cantante de la comunidad, para así llegar a planteamientos de gestión más participativos en donde el fin viene a estar direccionado a la preservación y sostenibilidad del patrimonio cultural como un recurso para el desarrollo local de cara al futuro.

El desarrollo, desde su acepción más amplia, está directamente relacionado con los elementos, recursos y condiciones de carácter transversal y puntual que tenga cada uno de los territorios. El patrimonio cultural se ha mostrado como uno de estos factores que puede jugar un papel protagónico en el territorio y presenta, además, la ventaja de hacer posibles procesos de desarrollo endógenos de carácter subnacional sin perder de vista su interrelación con elementos emergentes de carácter transcultural.

Defendemos en este artículo la existencia de territorios patrimoniales, que se definen básicamente por ser territorios periféricos dentro del desarrollo de los núcleos principales del país, cuentan con una comunidad asociada que ha sabido preservar los valores culturales de generación en generación y que en los últimos años se ha planteado que su patrimonio cultural puede convertirse en uno de los recursos principales para el desarrollo de su zona desde su gestión. Con un reciente enfoque cultural, el territorio traspasa la idea de representar un sustrato físico y recurso económico en el cual vivimos en toda la expresión de la palabra, a resignificarse a través de una dimensión patrimonial (Cañizares Ruiz 2014). Este concepto de territorio patrimonial es fruto de la evolución reciente de la idea de patrimonio cultural, una evolución que se manifiesta en cuatro campos fundamentales, que son la base de la línea de investigación que vengo desarrollando los últimos años.

En primer lugar, se pasa de concebir el patrimonio como la suma de elementos aislados de carácter monumental a incorporar nuevas formas, tanto de objetos y sujetos, relacionadas a un espacio determinado. Considerando así el contexto directo e indirecto para comprender estos territorios desde un punto de vista más integral. Esta visión se materializa en 1992 cuando se incluye la categoría de paisaje cultural dentro de la Lista del Patrimonio Mundial y que ha ido adoptando diferentes formas, según la visión y el con- 
texto en la que se enmarca. Incluso posiblemente estos criterios y definiciones adoptados en la última década del siglo pasado ahora se nos quedan cortos a la hora de observar los territorios patrimoniales desde distintas ópticas. A decir de Cañizares Ruiz (2014), un territorio percibido y valorado por sus cualidades culturales es producto de un proceso y soporte de la identidad de una comunidad.

También se puede apreciar que algunas propuestas de ordenación del territorio empiezan a prestar interés por atender a un nuevo binomio: naturaleza y cultura como partes de un concepto único, patrimonio. Y los paisajes culturales pueden constituir un vehículo para alcanzar el objetivo de construir entornos más diversos y cargados de identidad. Y para reactivar determinados territorios (Galindo González y Sabate Bel 2009).

En segundo lugar, se procede al paso desde la restauración y conservación técnica de estos monumentos a la concepción de los proyectos de intervención mucho más amplios y multidisciplinares, que incluirán la gestión de estos territorios como un elemento fundamental. Si hacemos referencia a un proceso para encarar estos proyectos como un ciclo, vemos que no solamente se analiza, estudia, propone e interviene, sino que se piensa de manera integral añadiendo la gestión a este ciclo que, por último, desembocará en otro de los cambios sustanciales del quehacer y la visión del patrimonio cultural, la sostenibilidad.

La incorporación de la idea de sostenibilidad es el tercer gran campo al que nos referimos. Esta idea está ligada básicamente al cambio de posición que puede llegar a tener el patrimonio cultural, esto es: de participante a protagonista dentro del desarrollo sostenible de los territorios. Es así que advertimos que pasa de considerarse un recurso pasivo a un recurso activo, de ser concebido como un gasto a toda ley para los Estados a consolidarse como elemento que rentabiliza la inversión, ya sea desde un punto de vista económico o social. Este fenómeno se puede ir observando tanto en su inclusión dentro de lineamientos internacionales, como en el desarrollo de políticas públicas específicas o transversales que ponderan este nuevo rol dentro de las estrategias de desarrollo de cada país.

Tal como indica Alicia Novick (2011), "en los últimos años, el debate acerca del contenido de los planes y proyectos de alcance territorial que se proponen como vectores de desarrollo local-regional ha incorporado el patrimonio cultural como recurso, marcando cambios en la concepción de las políticas territoriales que, en el marco de los modelos desarrollistas, soslayan lo cultural del desarrollo económico". Y, por último, y posiblemente el más importante en contextos del hemisferio sur, es el involucramiento activo de la comunidad de cara a su patrimonio cultural y la repercusión que pueden tener sus acciones directas, desde la definición del valor simbólico y la 
importancia que implica para su cotidianidad, hasta la participación desde el planteamiento de estrategias globales a la gestión del día a día de estos elementos patrimoniales. Espacio de análisis y discusión en el que se amplía la visión hegemónica del experto foráneo y la postura que pueda tener en la definición de los valores inherentes de los elementos. Contemplando así una sinergia de ambos "mundos", que pondrá en evidencia esas miradas a la hora de evaluar, intervenir, gestionar y utilizar estos elementos que pueden estar dispersos y asociados a un territorio patrimonial. Los territorios patrimoniales en definitiva y conceptualmente también podrían asumir el legado de la experiencia y del esfuerzo de una comunidad viviente dentro de una superficie acotada, lo que Sabaté denomina el lugar en la memoria (Sabaté Bel 2010).

Si analizamos los cuatro lineamientos a los que hacemos referencia en los párrafos anteriores y que han sido en gran medida objeto de estudio de varios autores y de preocupación de varios políticos, veremos que esta evolución en términos generales está direccionada a la integralidad y sostenibilidad del patrimonio cultural, desde una visión más amplia y acorde a la realidad en la que vivimos, y que creemos fundamentales dentro de una visión más democratizadora, integral y global a la que se ha encaminado.

Este artículo persigue contrastar estos nuevos planteamientos vinculados con la gestación del concepto de territorios patrimoniales en el hacer de dos ejemplos chilenos que presentan innovadores sistemas de gestión patrimonial: el archipiélago de Chiloé y la región de Arica y Parinacota. La innovación en la gestión destaca especialmente en el contexto chileno. El Consejo de Monumentos Nacionales es el ente encargado de la tuición y protección de los bienes patrimoniales en Chile, cuya composición, atributos y funciones se describen en la Ley 17288 de Monumentos Nacionales que entra en vigencia en 1970. Si bien esta entidad dependía del Ministerio de Educación desde su creación, a partir del año 2018, con la creación del Ministerio de las Culturas, las Artes y el Patrimonio, toda la estructura pasa a ser parte del nuevo Ministerio, dependiendo directamente de la Subsecretaría de Patrimonio Cultural, que a su vez se descentraliza en oficinas regionales en todo el territorio. Esta apuesta del gobierno chileno viene acompañada del diseño de nuevas estrategias y políticas públicas que en la actualidad se encuentran en proceso de entrar en vigencia, en la que se incluye la Ley de Patrimonio Cultural. Por el momento rige en la materia la ya nombrada Ley 17288, que establece cinco categorías de monumentos nacionales.

El respaldo y la declaratoria de los casos a los que nos referiremos a continuación están dentro de una de las categorías establecidas denominada monumento histórico que, en el artículo 9 de la propia ley, la define como "los lugares, ruinas, construcciones y objetos de propiedad fiscal, municipal o particular que por su calidad e interés histórico o artístico o por su antigüe- 
dad, sean declarados tales por decreto supremo, dictado a solicitud y previo acuerdo del Consejo de Monumentos". La implicación directa de este decreto con el monumento histórico se traduce en que cualquier intervención a ser realizada en este inmueble debe ser autorizada por el Consejo de Monumentos Nacionales. Esta condición de monumento histórico debe ser respetada por los planes reguladores que rigen el desarrollo urbano de cada comuna y estar relacionada con la normativa de cada una de las regiones.

El acercamiento personal a ambos territorios y modelos fue en dos niveles; el primero, una aproximación desde fuera, con una visión foránea, con visitas en los años 2013 y 2014 respectivamente; en el segundo, se realiza una visita más estructurada a ambos proyectos. Primeramente, un viaje de trabajo para conocer específicamente la labor de la Fundación Amigos de las Iglesias de Chiloé; posteriormente, en el caso de la Fundación Altiplano, para la realización de una estancia de investigación y trabajo por nueve meses. Esta experiencia de primera mano es acompañada con la revisión bibliográfica respectiva, entrevistas realizadas a personas claves en el último año, actualizando así tanto la información como la visión de los diferentes actores involucrados en estos territorios patrimoniales. Finalmente, en las conclusiones se contrasta la relación existente entre la teoría y la práctica, creando un posible diálogo entre ambos niveles para consolidar instrumentos más eficientes y eficaces a la hora de abordar la gestión de territorios patrimoniales con una visión integral.

\section{EL ARCHIPIÉLAGO DE CHILOÉ Y SUS CARACTERÍSTICOS VALORES CULTURALES EN RELACIÓN CON LA MISIÓN CIRCULAR Y LA ARQUITECTURA CHILOTA}

\section{Contexto}

Chiloé se constituye como un archipiélago del sur de Chile perteneciente a la X región de Los Lagos, cuyo principal territorio continuo insular es la denominada Isla Grande de Chiloé de 8.300 km² que, a la vez, está rodeada de 40 islas menores. Los principales asentamientos urbanos se desarrollan en la Isla Grande y se encuentran ubicados mirando al continente, dando lugar al denominado mar interior, sitio que por aspectos climáticos, geográficos, productivos u otros presenta mejores condiciones de vida para sus habitantes. Toda la región cuenta con 10 comunas $^{1}$ y $180.185^{2}$ habitantes, destacando tres focos demográficos dentro de la isla: Ancud, Castro y Quellón, con el $70 \%$ de los habitantes aproximadamente.

Chiloé, antes de la llegada de los españoles, era un territorio ocupado por chonos y huiliches. Los primeros habitantes, que datan de 5.000 años a. de C., vivían de la pesca y recolección de mariscos; mientras que los segun-

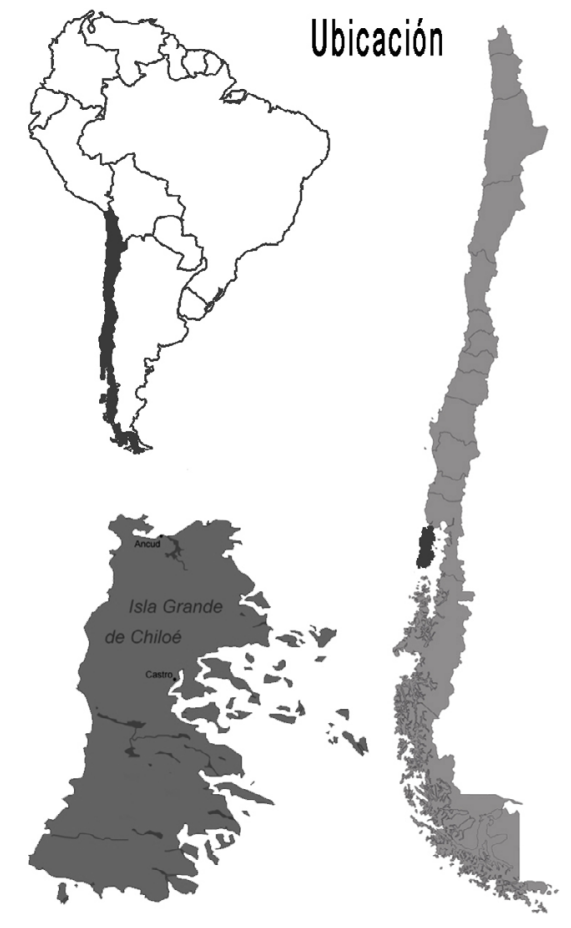

Ubicación de la Isla Grande de Chiloé | mapa elaboración propia

1

En Chile las comunas representan la división administrativa menor y básica, conocido en otros países como municipios.

2

Datos del Instituto Nacional de Estadística en 2017. 
3

Llegada del primer español a Chiloé en 1540 y la colonización iniciada en 1567 con la fundación de Castro.

\section{4}

El concepto de cultura de bordemar lo instala el taller Puerta Azul en su publicación Chiloé, cultura y bordemar (Rojas y Vivaldi 1979). Es el espacio que va entre el punto más alto $y$ más bajo de la marea, en zonas donde no existen costas. Término que está totalmente apropiado en la zona.

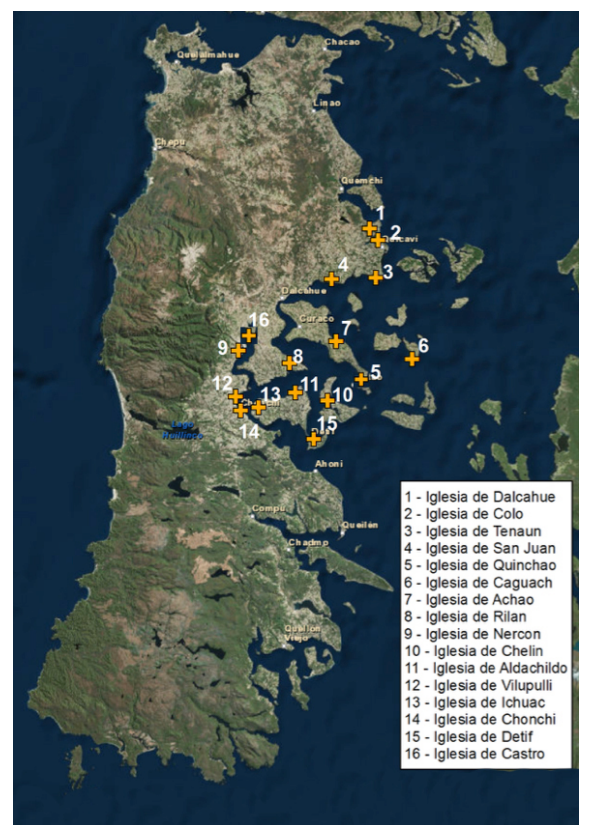

Mapa de Chiloé, ubicación de iglesias del Sitio de Patrimonio Mundial, 2018-2019 | fuente Fundación Altiplano (2019) dos asentados, desde 200 años d. de C., se caracterizaban por ser pueblos sedentarios que cultivaban la tierra y criaban animales menores. El primer contacto con españoles fue en el siglo $\mathrm{XVI}^{3}$; como pasaba con otros territorios del nuevo mundo, que no representaban mayor importancia para la corona española, Chiloé con su australidad, insularidad, aislamiento y pobreza, estaba destinado fundamentalmente a las misiones. De este modo, el sistema de evangelización llegó con los jesuitas en 1608, acorde al Tercer Concilio de Lima, que constituyó el elemento definitivo para la consolidación del poblamiento disperso y la forma de desarrollo cultural en el territorio chilote. En 1610 se inicia la primera misión marítima, luego muy conocida como la "Misión Circular", que consistía en recorrer a través de la navegación los poblados de todo el archipiélago en un ciclo anual establecido de acuerdo con los rituales y el calendario litúrgico. Este sistema tuvo mucho que ver con la organización local de la región y el territorio, que se repitió rigurosamente por más de 150 años, hasta la expulsión de los jesuitas en 1767.

La Misión Circular fue retomada a continuación por los franciscanos, que además respetaron los usos y tradiciones que se establecieron por la Compañía de Jesús. La historiadora Ximena Urbina considera que "reconocer la existencia de instituciones, tales como las de los fiscales y patronos; festividades religiosas propias de cada pueblo y el compromiso de hacer avanzar la conquista espiritual" fueron las decisiones más acertadas adoptadas por los franciscanos. El mayor aporte de la orden de San Francisco de Asís estaba referida a la implementación de la torre fachada en la construcción de las iglesias que se sumaban a la explanada anterior, el volumen horizontal, la bóveda y las técnicas constructivas, elementos que consolidarían su tipología (Urbina Carrasco 2009).

A partir de 1840, cuando se creó el Obispado de Ancud, continúa el modelo con las denominadas visitas pastorales que, salvando las diferencias, es lo que se viene realizando hasta nuestro días.

El archipiélago de Chiloé conforma un universo cultural y natural con características únicas. El tradicional aislamiento en el que se desenvolvió la sociedad chilota y que llega hasta nuestros días es un factor importante en la conservación de prácticas religiosas y culturales que reflejan el intenso mestizaje e intercambio que se realizó entre ibéricos e indígenas.

En ese sentido, tanto la geografía como la historia del archipiélago, en sus distintos periodos, dieron origen a una cultura cuyas costumbres tradicionales poseen una identidad propia y distinta, si las comparamos con las del centro de Chile, que representa el principal núcleo social y económico del país, o las del norte, que responden a lógicas de mestizaje y culturas étnicas distintas. Entre estas características propias y únicas, podemos destacar el trabajo y manejo de la madera y el asentamiento de bordemar4; ambas 


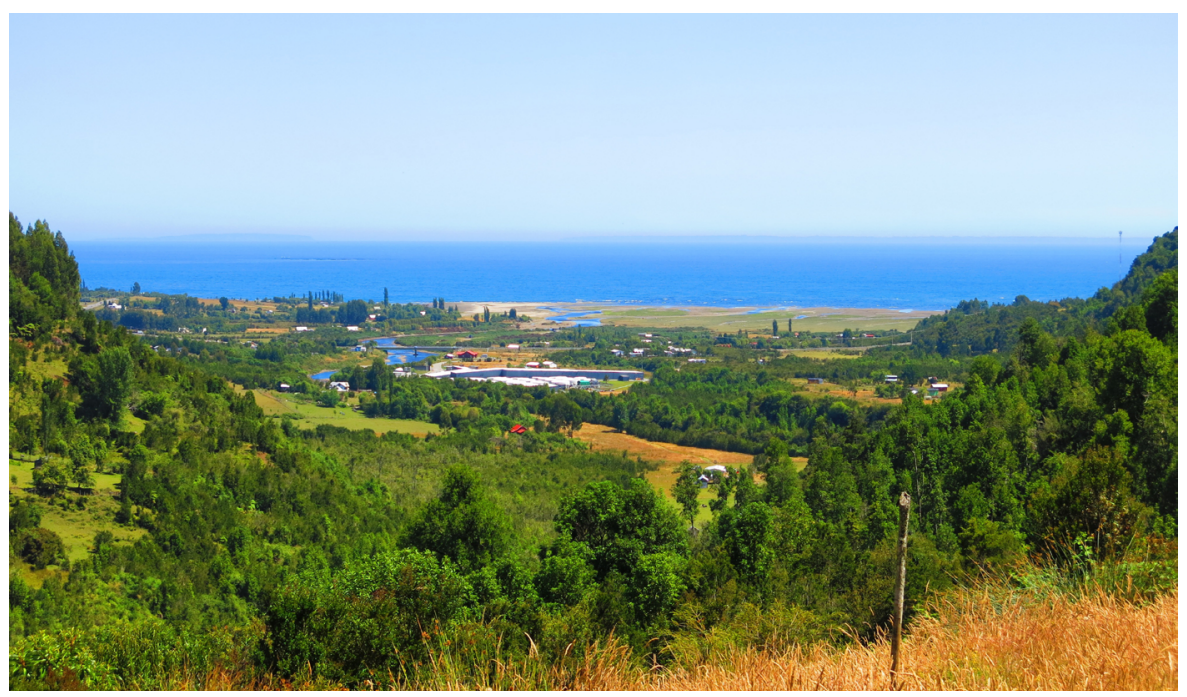

se encuentran arraigadas al proceso social, territorial e histórico inherente al archipiélago.

Una de las manifestaciones más importantes de la identidad chilota tiene relación con la religiosidad popular, que se refleja en el gran número de iglesias construidas y activas en todo el archipiélago que en su mayoría pertenecen a la denominada Escuela Chilota de Arquitectura Religiosa en Madera, y que actualmente suman alrededor de ciento veinte ${ }^{5}$, destacándose una selección de dieciséis que cuentan con la declaratoria de patrimonio de la humanidad desde el año 2000. Las características y los valores de excepcionalidad se sustentan en los criterios culturales (ii) ${ }^{6}$ y (iii) $^{7}$ definidos por la Unesco.

La mayoría de estas iglesias fueron construidas entre la segunda mitad del siglo XIX y principios del XX, destacando por ser una arquitectura única en América, principalmente por las técnicas constructivas de madera utilizadas, extrapoladas principalmente de la carpintería de ribera y los conocimientos transferidos por los misioneros. Su construcción y mantenimiento era parte de un trabajo de "minga"8 característico de la zona, que enfatiza los valores sociales reflejados en la solidaridad, generosidad y participación. Y es que la participación de toda la comunidad en la construcción de los templos, a través de la aportación de trabajo, herramientas y materiales, era la base fundamental. Los pobladores se constituían como propietarios de las capillas y el trabajo de manutención era una labor encomendada a los comités de capilla en coordinación con los párrocos y sacerdotes. Las iglesias en Chiloé fueron construidas en la red de espacios de reunión y usos comunitarios que ocupaban los grupos étnicos antes de la llegada de los misioneros, en cada uno de los pueblos.
Bordemar de la Isla Grande de Chiloé, 2016 | foto Marta Piech

5

Datos obtenidos en relevamiento realizado para el Inventario de Iglesias de la Escuela Chilota de Arquitectura Religiosa en Madera publicada en 2019 por la Subsecretaria de Patrimonio Cultural del Gobierno de Chile.

Testimoniar un importante intercambio de valores humanos a lo largo de un periodo de tiempo o dentro de un área cultural del mundo, en el desarrollo de la arquitectura, tecnología, artes monumentales, urbanismo o diseño paisajístico.

7

Aportar un testimonio único o al menos excepcional de una tradición cultural o de una civilización existente o ya desaparecida.

8

Sistema de trabajo comunitario o colectivo con fines de utilidad social que se realiza, con algunas diferencias, en la mayoría de las culturas en América Latina. 


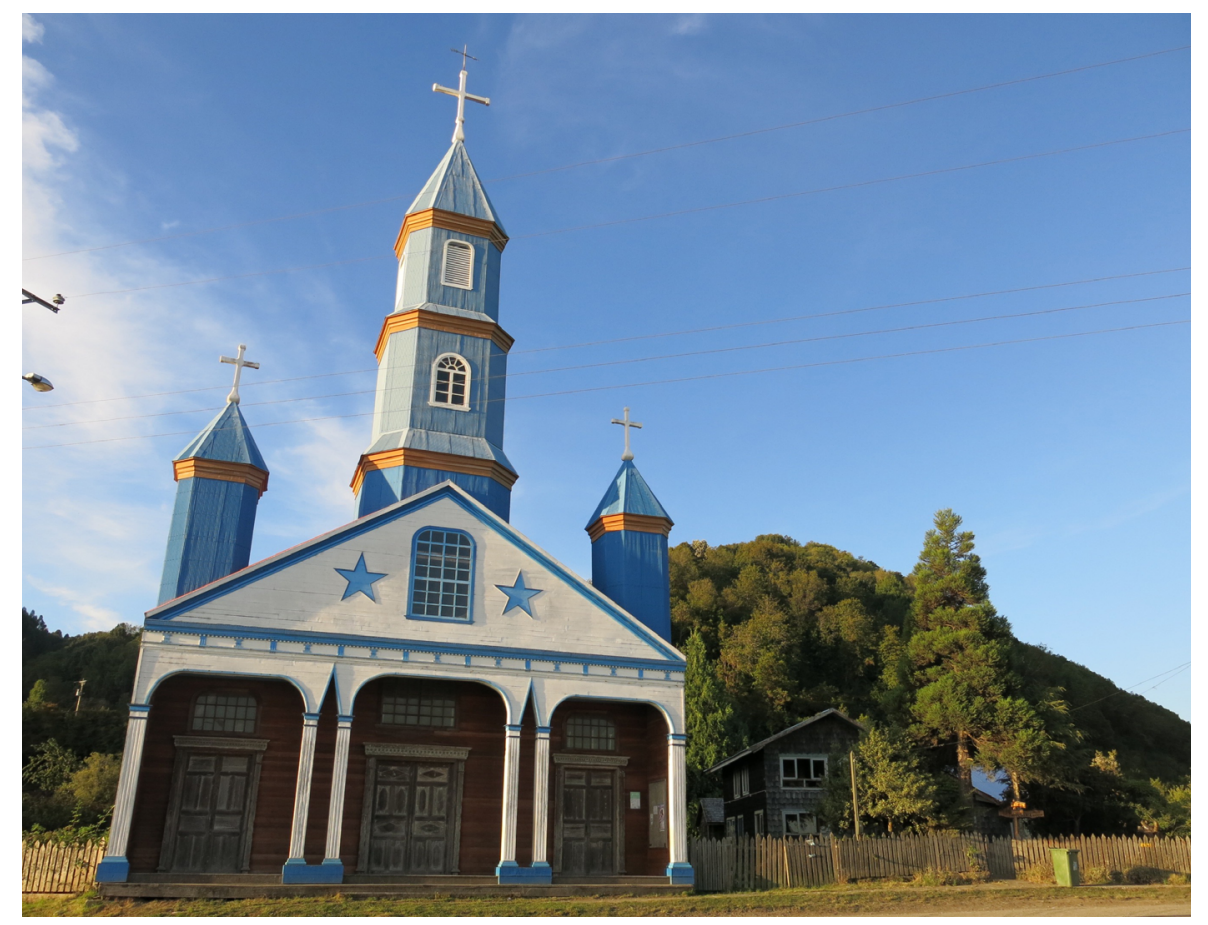

Iglesia de Tenaún, 2016 | foto Cinthia Giménez

\section{Modelo de gestión}

Las iglesias que nacen producto del oficio de los carpinteros de ribera y la voluntad de las comunidades por trabajar unidos en una causa común vinculada a las antiguas misiones evangelizadoras de la zona, y que representa una característica de la identidad chilota, se ven amenazadas por el cambio generacional y la tendencia de las nuevas generaciones de buscar otros oficios en las industrias asentadas en la isla a partir de los ochenta del siglo pasado. Este interés por buscar diferentes maneras de vida desfavorece la continuidad del oficio y las técnicas constructivas referentes de la región, solamente en manos de los antiguos carpinteros.

Es así que prevalece una preocupación latente por la forma de gestionar este patrimonio cultural para evitar la pérdida de su valor intrínseco ligado a la identidad chilota. El inminente paso del tiempo y la escasa iniciativa del gobierno central para detener la desaparición de las iglesias de la Isla de Chiloé llevaron a crear, en el año 1976, reforzado en 1998, el Programa de Protección y Desarrollo del Patrimonio Arquitectónico de Chiloé, a través de un convenio establecido entre el Obispado de Ancud y la Facultad de Arquitectura y Urbanismo de la Universidad de Chile. Las primeras acciones encaradas por este programa estuvieron relacionadas con el estudio de las manifestaciones más significativas de la arquitectura chilota. Iniciativa a la que se unieron posteriormente varias instituciones académicas públicas 
y privadas, además de las comunidades locales. Este trabajo consistió principalmente en llevar a cabo un inventario de las iglesias, junto con todas las características técnicas de la arquitectura chilota en madera, documento e investigación que posteriormente fue uno de los contenidos principales que nutrieron el expediente para su inscripción en la Lista de Patrimonio Mundial ${ }^{9}$. En esta misma etapa se declararon las primeras siete iglesias como monumento histórico: Achao, Quinchao, Castro, Rilán, Nercón, Vilupulli y Chonchi.

Ya en el año 1993, se consolidó la creación de la Fundación Amigos de las Iglesias de Chiloé $^{10}$, institución sin fines de lucro que nace con la misión de preservar el patrimonio cultural relacionado con las iglesias chilotas, tipificadas dentro de la Escuela Chilota de Arquitectura en Madera. Los primeros trabajos encarados por esta fundación fueron la restauración integral de 13 iglesias prioritarias y el establecimiento de un taller de formación continuo de carpintería en sus primeros años de vida; paralelamente, en este periodo se declararon monumento histórico las iglesias de Aldachildo, Ichuac, Detif, Tenaún, Colo, San Juan y Dalcahue.

Trabajos que se fueron complementando con otras intervenciones e iniciativas que se estructuraban en cinco áreas prioritarias que encaró la Fundación: dirección, administración, escuela de carpinteros, restauración de la identidad, conservación y restauro en obra y administración. Acciones a las que teóricamente se sumaban las comunidades, que siguen siendo las encargadas de la administración de las iglesias y manifestaciones culturales a través de sus estructuras locales.

Posteriormente, en el año 2000, se realizó la visita de una de las comisiones de ICOMOS para hacer la evaluación del sitio. La recomendación más pertinente y significativa estaba referida a la posible ampliación de la superficie de protección, la opción de convertirla en área de amortiguamiento de cada iglesia y la declaratoria de monumento nacional de la iglesia de Caguach y Chelín. El resultado de esta visita fue la elaboración y aprobación de las zonas típicas o pintorescas, que dentro de la normativa chilena corresponden a estructuras urbanas tendientes de protección especial, fortaleciendo también la idea de una conservación más integral del conjunto. Entre el año 2000 y 2016 se elaboraron y declararon zonas típicas los entornos de los monumentos de diez de las iglesias pertenecientes a Chiloé.

La fundación Amigos de las Iglesias de Chiloé, con estas áreas de trabajo y su estructura tanto técnica como financiera, funcionó hasta el año 2017; a partir de ese momento, se ha venido trabajando en un replanteamiento de la estructura de gestión, para que responda a las nuevas políticas públicas y la legislación vigente en Chile. Este trabajo se realiza desde la oficina de gestión de sitios patrimonio de la humanidad y es financiado íntegramente por fondos públicos.
9

Los principales impulsores de la declaratoria de las iglesias de Chiloé como patrimonio de mundial fueron los arquitectos Hernán Montecinos y Lorenzo Berg y el Senador por la Región Sergio Páez, además de la gestión del Ministerio de Relaciones Exteriores como Estado Parte.

10

Dos elementos fundamentales jugaron a favor para la creación de la institución: consolidar un modelo de gestión que se incluía en las recomendaciones de la Unesco y paralelamente una fuerte temporada de lluvias que causó considerables daños en los principales edificios.

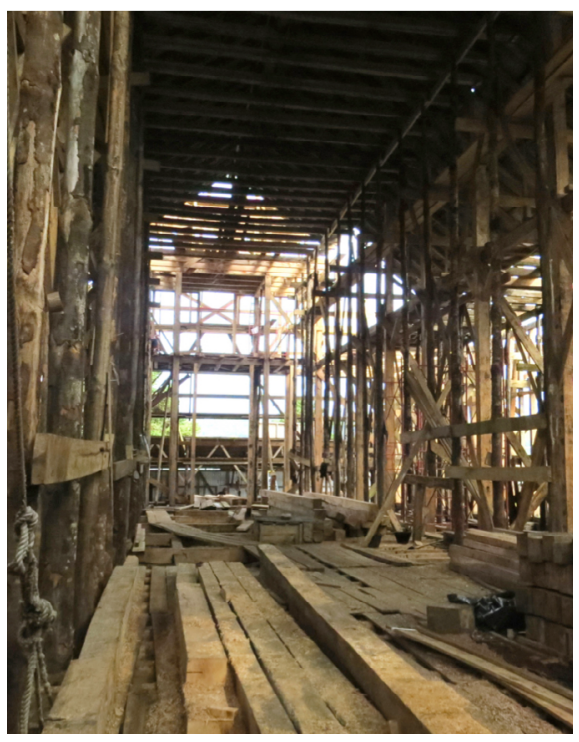

Restauración integral de la Iglesia de Dalcahue, 2014 | foto Cinthia Giménez 


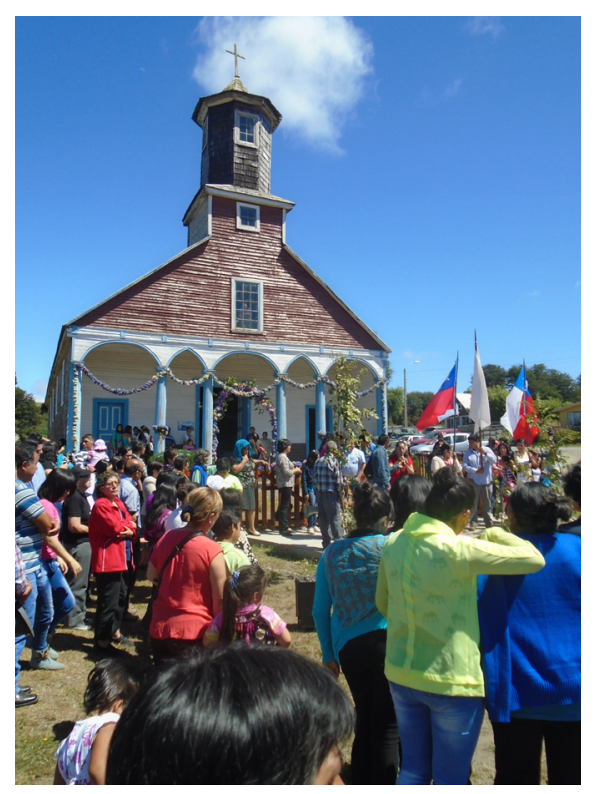

Fiesta de la Candelaria en la Iglesia de Puchilco, 2016 | foto Cinthia Giménez

Trabajo de campo de la autora, visita a la sede de la Fundación Amigos de las Iglesias de Chiloé en 2016 | foto Tanya Durán

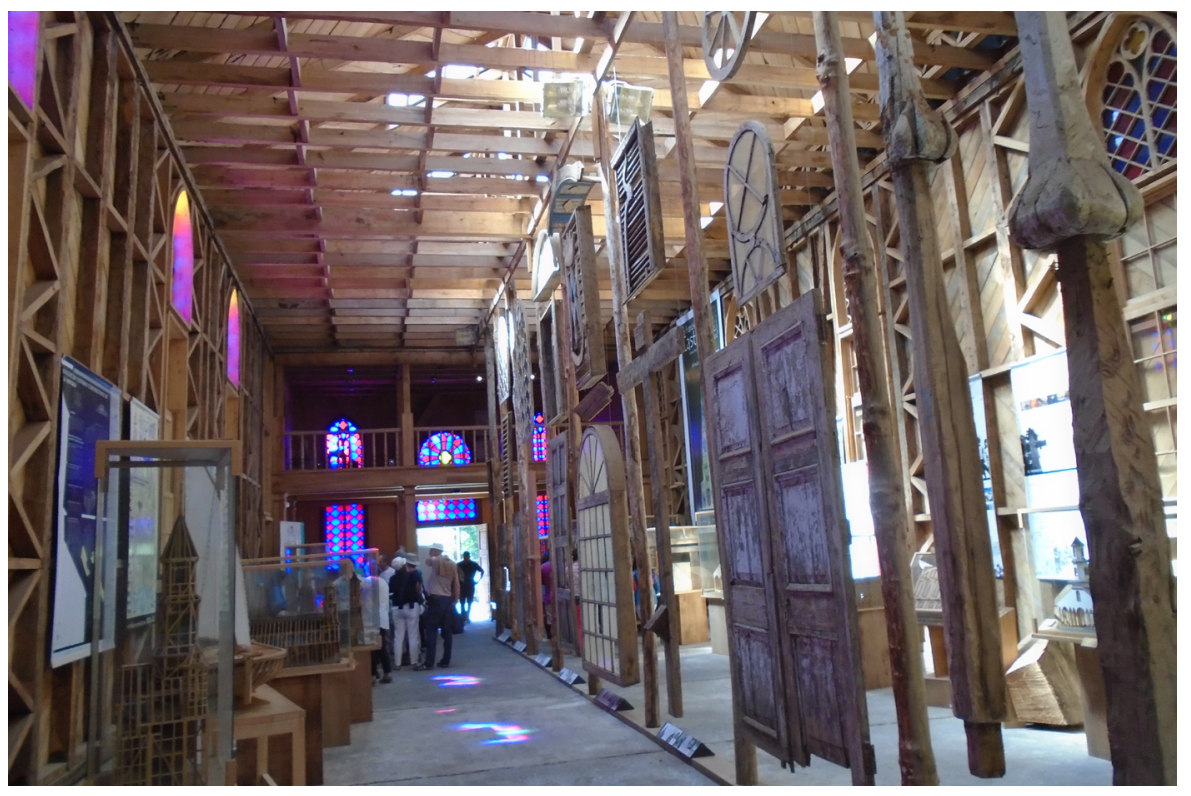

En el año 2019 se realiza una actualización del inventario y de los valores asociados a este conjunto patrimonial destacado e importante en el país, estudio que se plantea desde una mirada integral del acervo cultural de Chiloé. Es el primer ejercicio que se realiza en esta zona, donde se entiende y comprende la evolución e influencia de la arquitectura religiosa chilota de manera integral en el territorio, junto con sus valores ponderados, y qué significa esto para el desarrollo. Se amplió el área de estudio a todas las construcciones con las características singulares de la Escuela de Arquitectura Chilota, que va más allá de las 16 declaradas patrimonio mundial o las aproximadamente 80 que se levantaron en el estudio previo realizado antes de la elaboración del expediente en el año 1999. Este nuevo inventario concluye con 152 iglesias y todas las actividades de patrimonio cultural inmaterial asociadas a estas comunidades. Esta actualización de información en vinculación directa con la nueva estructura y visión de la institucionalidad chilena debería ser capaz en los próximos años de encaminar los procesos integrales de gestión de este territorio patrimonio en el sur de Chile.

Chiloé muestra un modelo de conservación de bienes inmuebles con mucha inercia política-centralista. Vemos que, si bien la comunidad es totalmente activa en las fiestas religiosas y el patrimonio cultural inmaterial asociado a las iglesias, dicha comunidad no tienen un rol protagonista en la gestión, estando ausente en la decisión de las acciones sobre el quehacer de las iglesias, principalmente las que tienen declaratoria nacional o internacional. En este sentido, la Oficina Nacional de Sitios Patrimonio Mundial está trabajando para fortalecer esta visión con el objetivo de hacer partícipes a todos los actores en un nuevo planteamiento de modelo de gestión integral. 


\section{LA RUTA DE LA MISIONES DE ARICA Y PARINACOTA, HACIA LA CONSOLIDACIÓN DE UN PAISAJE CULTURAL DE LA REGIÓN SUR ANDINA}

\section{Contexto}

Arica y Parinacota, región del norte chileno, colindan con Perú y Bolivia, y en su ámbito más amplio y transnacional, es conocida como territorio sur andino. La característica principal de esta zona es que en menos de 200 kilómetros se puede estar en cuatro pisos ecológicos distintos: altiplano, precordillera, valles y costa; bajando desde 4.700 a 0 metros sobre el nivel del mar. Esta región se divide en cuatro provincias: Arica, Camarones, Putre y General Lagos. Los habitantes de toda la región son 226.068 habitantes ${ }^{11} y$ su capital Arica aglutina aproximadamente el $95 \%$.

El registro cultural en esta región se remonta a más de 9.000 años. Los pertenecientes a la cultura chinchorro fueron los primeros pobladores de la costa. Posteriormente, y ya entre valles y cordillera, fue habitada por señoríos aimaras con alguna influencia quechua. Los asentamientos se desarrollaban en franjas que iban desde la cordillera a la costa integrando poblados de los diferentes pisos geológicos. Pequeñas poblaciones vivían del pastoreo y la agricultura. Estas rutas, que conectaban el altiplano con la costa y cruzaban el territorio de norte a sur, ya establecidas tanto longitudinal como transversalmente, estaban constituidas como una red de caminos prehispánicos que luego fueron utilizados por los conquistadores, dando lugar al hecho histórico más relevante de este conjunto patrimonial: la ruta de la plata. A lomo de mula se transportaba el mineral desde el cerro rico de Potosí hasta el puerto de Arica, para luego enfilar rumbo a Sevilla, desde el año 1574.

La historiadora chilena Magdalena Pereira afirma: "La administración española instaura el sistema de reducciones para el sometimiento y evangelización de las comunidades indígenas y se construyen templos rústicos de adobe, piedras y paja brava, que albergan la misión y constituyen uno de los conjuntos patrimoniales más destacados de América, revelándose como manifestaciones estéticas del barroco andino y exquisitas fuentes históricas de un proceso cultural complejo" (Pereira Campos 2019).

Arica y Parinacota, tras la independencia, fue territorio peruano hasta el año 1883. Después de la Guerra del Pacífico, pasa a consolidarse como territorio chileno. La instalación del ferrocarril Arica-La Paz en 1904 reactiva la ciudad como puerto natural del altiplano. Luego se produce una gran sequía, el cierre de las salitreras y una gran migración de los pueblos del interior hacia la ciudad capital. Es así que en la década de los sesenta del siglo pasado, se ve la disminución de la fuerza de trabajo en las comuni-
11 Datos del Instituto Nacional de Estadística en 2017

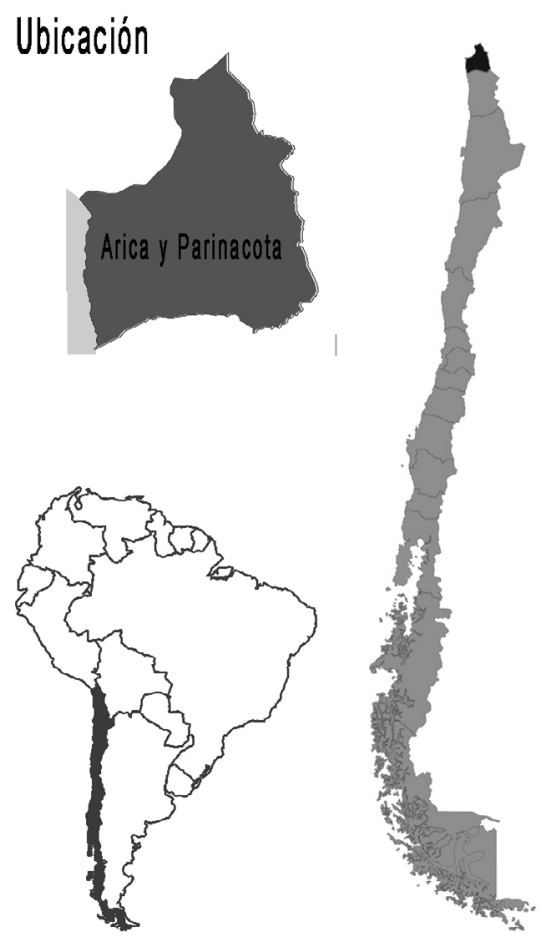

Ubicación de la región de Arica y Parinacota | mapa elaboración propia 

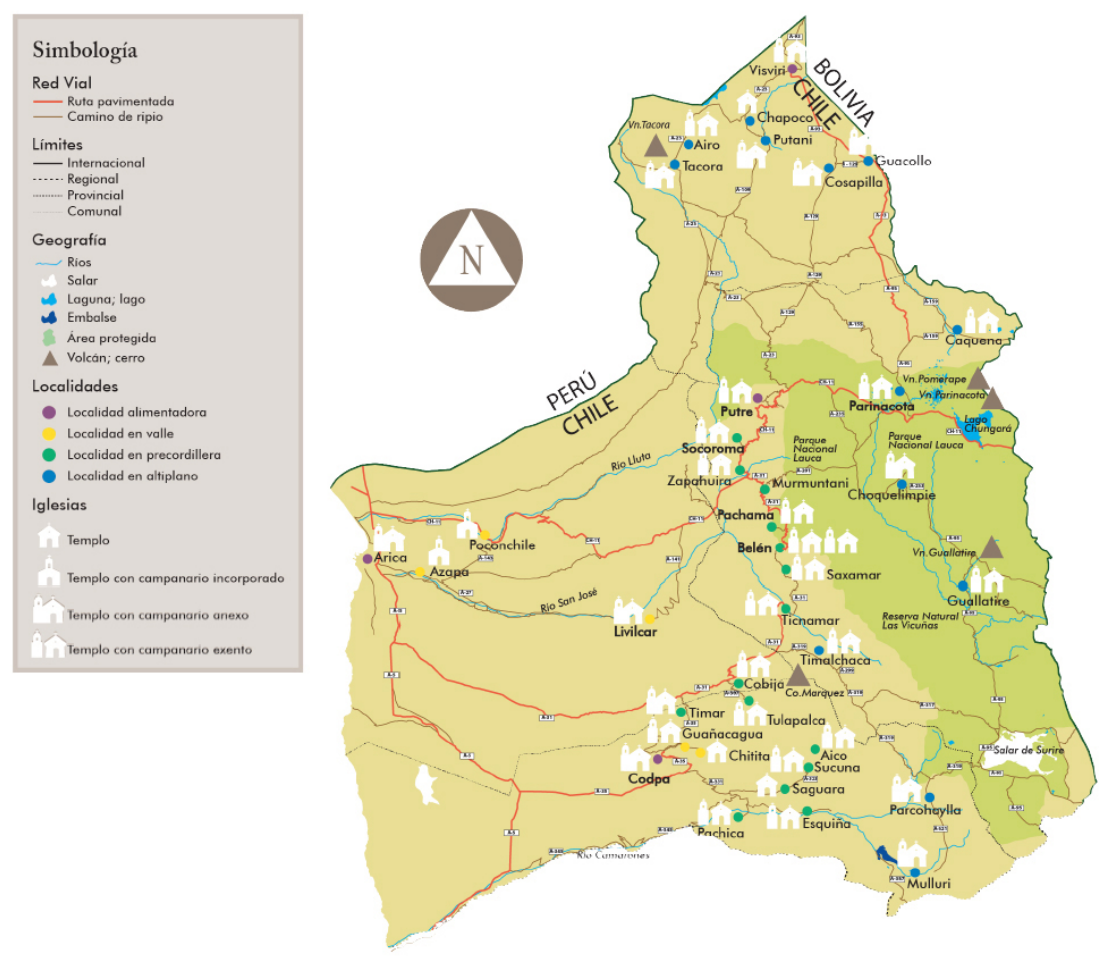

Mapa de Arica y Parinacota, con ubicación de iglesias del altiplano, 2019 | fuente Pereira Campos (2019)

Ser un ejemplo eminente de formas tradicionales de asentamiento humano o de utilización tradicional de las tierras o del mar representativas de una cultura (o de culturas), o de la interacción entre el hombre y su entorno natural, especialmente cuando son vulnerables debido a mutaciones irreversibles. dades andinas, principalmente en la agricultura y ganadería, dejando las tierras en descanso hasta los años noventa aproximadamente. Este despoblamiento naturalmente estuvo acompañado del abandono cotidiano de los templos, ya que solo se retornaba a los pueblos de interior para las fiestas de guardar.

La XV región de Arica y Parinacota se crea en 2007. Cuenta con una superficie de $16.800 \mathrm{~km}^{2}$. Anteriormente dependía de la región de Tarapacá. La creación de la región está ligada a la idea de recuperar la prosperidad lograda por el decreto de puerto libre y la gestión de la Junta de Adelanto entre 1956 y 1976, medidas que claramente mostraban la postura del Gobierno de Chile de generar desarrollo en esa zona.

En la actualidad, la conectividad cultural, económica, geográfica y social de índole tripartita entre los tres países fronterizos que conforman la región sur andina sigue vigente; Arica es el puerto "natural" de Bolivia sobre el océano Pacífico.

La excepcionalidad de la ruta de las misiones del norte de Chile se podría enmarcar en el valor histórico, arquitectónico-estético y cultural devocional. Como establecen los criterios culturales definidos por la Unesco, se sustenta por los criterios (ii), (iii) y $(v)^{12}$. En el año 1998, cuando se incluyen 


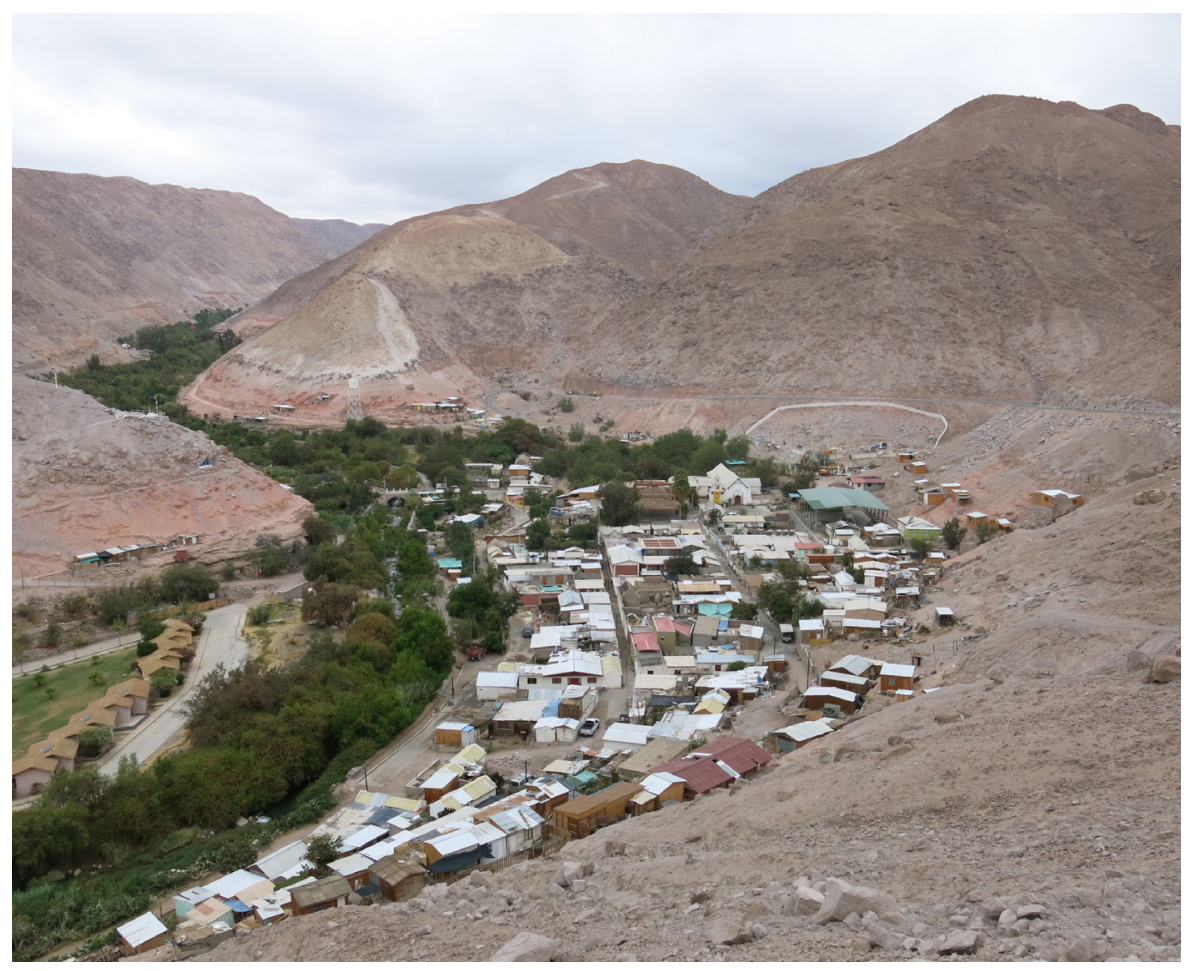

Valle y poblado de Codpa, 2015 | foto Cinthia Giménez

ocho de las iglesias de esta región dentro de la lista indicativa de Chile, solamente tenían declaratoria de monumento nacional en la región, como elementos representativos excepcionales del extremo sur del país, la Iglesia de Parinacota, como monumento histórico, y todo el pueblo de Parinacota como zona típica, gestión que se realizó en el año 1979.

En toda la ruta, los templos se consolidan como el escenario principal del sincretismo cultural de la comunidad, que se traduce en las manifestaciones culturales, tradiciones y costumbres que aglutinan baile, música, relatos orales, agricultura, ceremonias. Todas estas actividades, junto con el sistema de administración de origen colonial que sigue vigente basado en cargos tradicionales de mayordomos, fabriqueros y alféreces, han sido la base para la conservación de todo este patrimonio cultural hasta la actualidad.

Los templos que se construyeron para la misión de evangelización de los nativos a la llegada de los misioneros a finales del siglo XVI se enmarcan dentro del conocido Barroco andino. "Representan un grupo significativo de arquitectura de origen popular, no profesional, que mantuvo continuidad durante siglos"13. En la región existen más de 80 templos, teniendo en cuenta pequeñas capillas y se asientan en los diferentes pisos geológicos de la región.

13

Descripción que se refleja en la lista indicativa de Chile en Unesco, 1998. 


\section{Modelo de gestión}

En 1996, a la llegada a la zona del padre Amador Soto, misionero del decanato andino del Obispado de Arica, le surge una inquietud al observar el estado lamentable de conservación en el que se encontraban los templos de toda la región. Se suman dos factores para este decaimiento de los pueblos del interior: la inexistencia de recursos destinados a las intervenciones de conservación y, por otro lado, el despoblamiento al que se habían visto afectados los poblados por falta de oportunidades en la zona. Es así que a través de gestiones propias consigue el apoyo de grupo de estudiantes que vendrían a colaborar en las labores básicas destinadas a evitar la pérdida de estos testimonios de patrimonio cultural de la zona, especialmente los denominados templos andinos. Esta iniciativa representa una pieza fundamental para el inicio de la implicación de las comunidades y la visión a futuro para implementar una gestión del patrimonio más innovadora y participativa, y fundamentalmente como base del desarrollo local del territorio. Posteriormente el mismo grupo, junto con el misionero, se embarca en una labor de recopilación de información e inventario de 31 iglesias y capillas repartidas por el territorio, que se convierte en el antecedente directo para la elaboración del Plan de Restauración de Iglesias Andinas de Arica y Parinacota, llevado a cabo entre los años 2003 y 2006, ya como una de las primeras actividades de la Fundación Altiplano Monseñor Salas Valdés (FAMSV), que se creó como una institución sin fines de lucro hacia el año 2002 con el objetivo de velar y gestionar este patrimonio cultural en coordinación con las comuni-

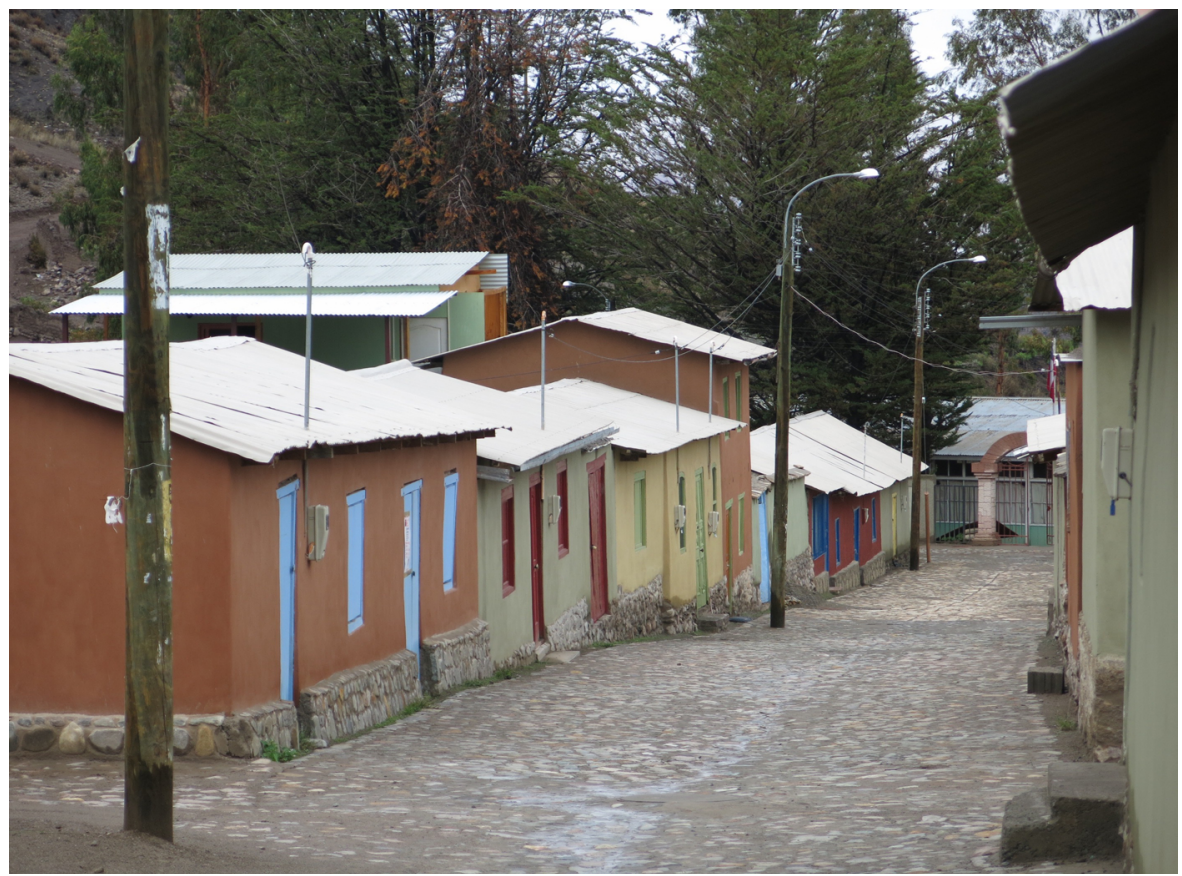


dades y la Iglesia Católica. La participación de la comunidad comprende el mantenimiento y limpieza del templo, las imágenes y la organización de las fiestas del calendario ritual, trabajo que históricamente estaba encabezado por fabriqueros y mayordomos.

Posteriormente, como parte del trabajo realizado por la Fundación Altiplano, entre los años 2005 y 2017, se declaran 32 iglesias como monumento histórico. Este trabajo viene acompañado con el desarrollo del expediente de Unesco para actualizar la postulación dentro de la lista indicativa que va más allá del planteamiento inicial que se hizo en su momento, encaminando la postulación a ser paisaje cultural, por las características culturales, sociales y naturales actuales que se han conservado con el tiempo.

Un hito importante se da con la primera gran intervención. Se realiza en el año 2009 y gracias a esto se llega a implementar una estructura y un modelo de gestión basado en la transferencia de conocimientos y fortalecimiento de la mano de obra y las capacidades locales instaladas. Los recursos económicos para realizar todas las acciones tienen un espectro bastante amplio, desde fondos públicos asignados directamente, obtenidos por concursos, hasta donaciones y aportes privados no solo de Chile sino de otros puntos del planeta.

Finalmente, uno de los resultados palpables que ponen en evidencia esta evolución del trabajo y el enfoque es uno de los últimos proyectos enca-

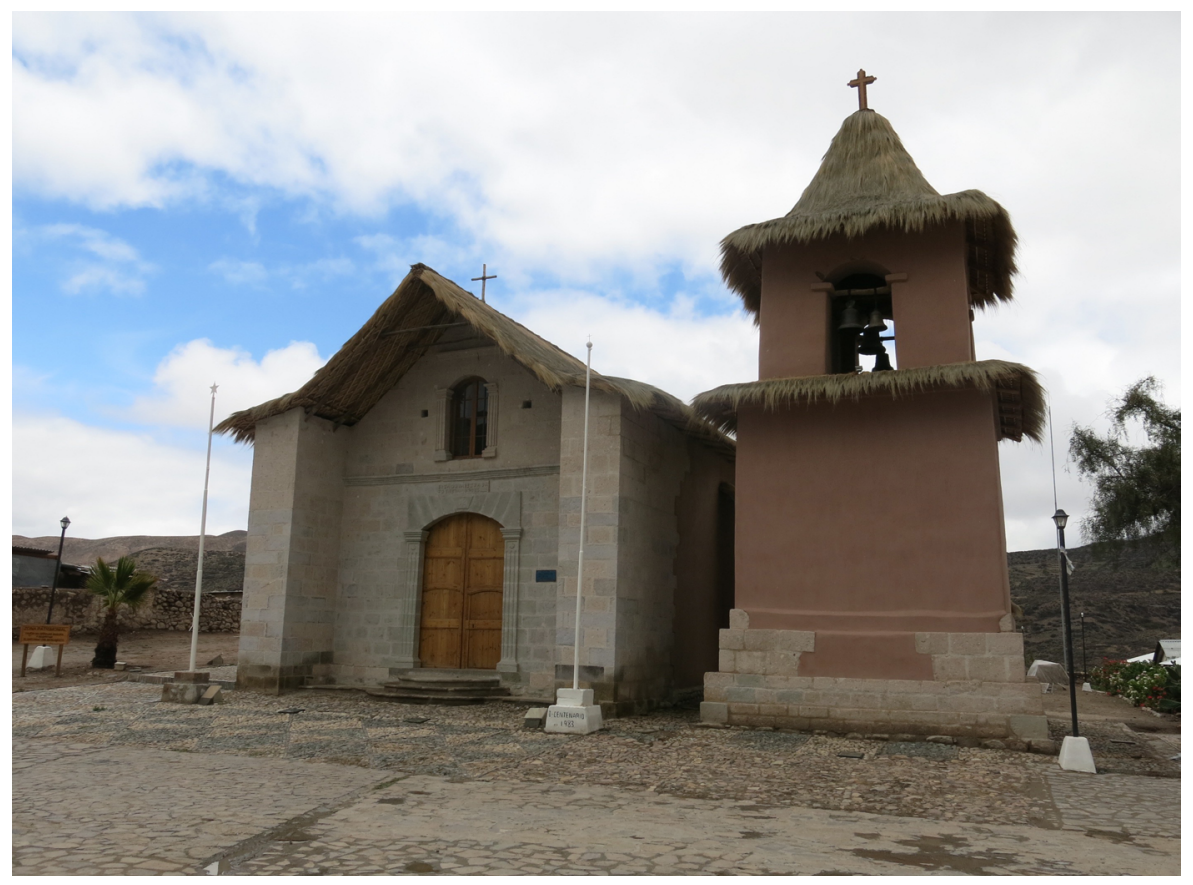

Iglesia de Socoroma, 2015 | foto Cinthia Giménez 


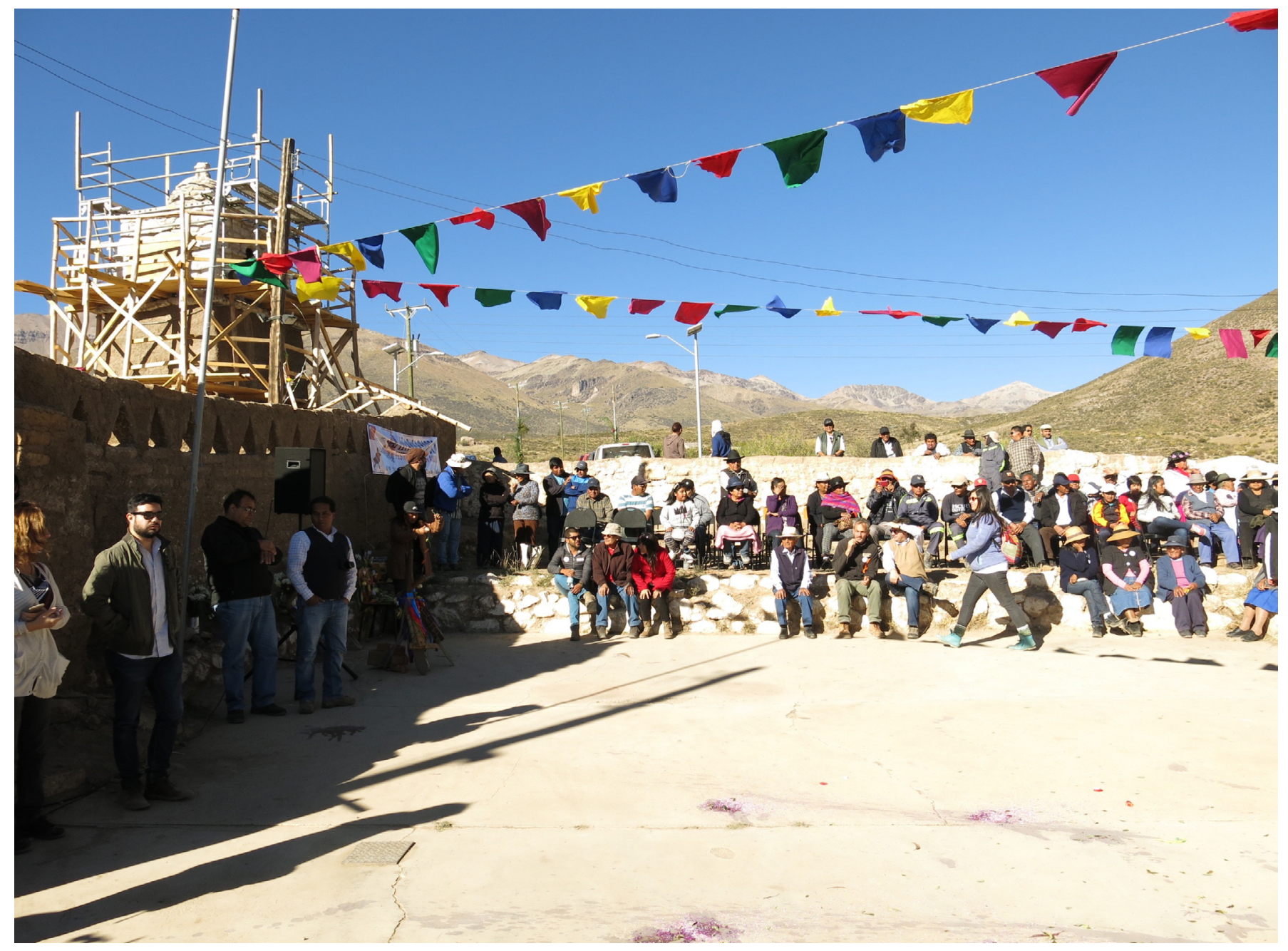

Festival Arica Barroca en Pachama, 2016 | foto Cinthia Giménez

rados, denominado reforzamiento de la gestión de la ruta de las misiones, que se enfoca como una actualización del Plan de Restauración de Iglesias Andinas de Arica y Parinacota iniciado en 2003. En este nuevo proyecto, concluido en 2019, se trabaja de manera mucho más integral consolidándose la estrategia en tres líneas fundamentales: conservación, creación y gobernanza del valor.

Los trabajos realizados y la puesta en marcha de procesos de intervención, apropiación y gestión de este patrimonio cultural con base a la prueba y error en las últimas dos décadas constituyen un precedente importante a la hora de la elaboración de políticas públicas vinculadas al desarrollo y al patrimonio cultural desde esta nueva institucionalidad del gobierno chileno. El principal desafío a mediano y largo plazo es que el modelo de desarrollo sostenible de una región, fronteriza y rezagada, esté basado en la conservación 
del patrimonio cultural y que se convierta en un ejemplo inédito para el país. La visión orientada hacia ponderar el patrimonio cultural como un recurso fundamental para el desarrollo sostenible de este territorio patrimonial es uno de los ejes fundamentales que defiende el modelo que se basa en tres grandes áreas, que a la vez se va readaptando y reorientando, para mejorar los procesos y satisfacer las necesidades reales de la región en este ámbito.

\section{CONCLUSIONES Y REFLEXIONES FINALES}

Si analizamos comparativamente y realizando un contraste con el marco conceptual que abraza este artículo, llegamos a sacar conclusiones bastante certeras e interesantes que pueden hacernos reflexionar sobre el actuar y el quehacer de los modelos de gestión en territorios patrimoniales.

Si bien los dos casos se desarrollan en contextos muy distintos, por sus características territoriales, ambientales y culturales, podrían considerarse territorios patrimoniales únicos, que se encuentran en enclaves culturales excepcionales y que corresponden a regiones que han estado olvidadas y marginadas de la lógica de desarrollo principal de las políticas públicas nacionales, factor que ayudó notablemente a la conservación de los mismos. Ambos casos se ven mellados en el estado de conservación de su patrimonio por diferentes motivos: Chiloé, debido a la búsqueda de nuevas formas de vida de sus pobladores con la llegada de grandes industrias salmoneras $\mathrm{y}$, en el caso del norte, por el despoblamiento evidente que se inició debido a las sequías y la falta de posibilidades reales de trabajo en el interior.

Cabe recalcar que con la evolución del concepto de patrimonio cultural y las últimas acciones desarrolladas en ambos territorios patrimoniales, se ve una concepción más amplia que se refleja en los últimos proyectos encarados. Tiene mucha lógica, teniendo en cuenta que las iglesias en ninguno de sus momentos históricos fueron entes aislados, sino que respondían a una dinámica territorial, productiva, natural y a unas bases culturales identitarias propias de cada región. De tal manera que los primeros instrumentos elaborados para la conservación y preservación de este patrimonio fueron concebidos independientemente para cada uno de los monumentos, con énfasis en el elemento físico y el valor estético e histórico del edificio. La visión y el nacimiento de los modelos de gestión de patrimonio responden a la misma lógica, identificación e inventariado de patrimonio cultural material a partir de iglesias dispersas relacionadas con un territorio y que responden a una razón de ser de la época colonial.

Posteriormente se inicia una fase que contempla la intervención integral de los edificios, según necesidades y priorización de las actuaciones, para concluir más adelante en el desafío en el que se encuentran en la actualidad:

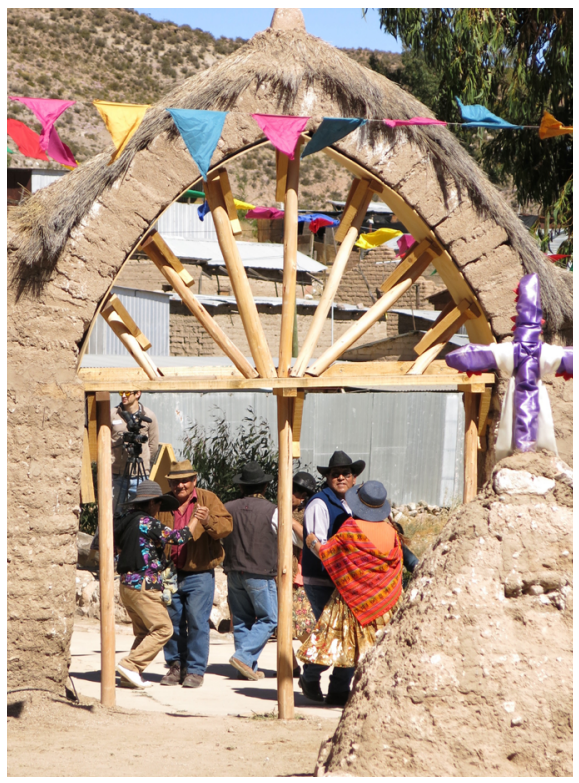

Baile tradicional en el atrio de la iglesia de Pachama, 2016 | foto FAMSV 
la conservación sostenible de territorios patrimoniales bajo una visión más integral, incidiendo en políticas públicas para la mejora de la calidad de vida de las comunidades. Para cumplir este objetivo es primordial la involucración activa de las comunidades a la hora de tomar decisiones sobre su patrimonio cultural, cosa que en principio no era tan evidente ya que la idea de conservar y salvaguardar este patrimonio venía con una visión exógena y expertos que llegan de otras zonas y realidades a trabajar con organismos locales. La reflexión que se hace sobre este punto está muy ligada al hecho que los pobladores de las regiones tienen asumidos todos los valores patrimoniales dentro de su vida cotidiana y no como elementos excepcionales que puedan contar con otros valores diferentes a los que ellos le dan.

También se evidencia que en la zona norte se apuesta por plantear una nueva matriz de desarrollo incluyendo el patrimonio cultural dentro de las políticas públicas y utilizar el resultado del trabajo de los últimos años en la toma de decisiones más acertadas dentro del aparato estatal para ser extrapoladas a otras regiones. En el caso de Chiloé, vemos que hasta la actualidad la estrategia y la gestión siguen dependiendo de una estructura central, en donde recién hay un acercamiento con el territorio. Hay una evidente diferencia en la respuesta a los edificios patrimonio mundial y el resto, sesgando así esta amplitud del concepto integral de todo el territorio.

Finalmente, podemos concluir que ambos territorios patrimoniales, regidos bajo una legislación obsoleta y un aparato estatal muy burocrático, han sabido ir por delante y se han convertido extraoficialmente, con pros y contras, en laboratorios experimentales. Han asumido las decisiones y acciones tomadas día a día como evidencia también las diferentes visiones de los modelos. El elemento fundamental es el trabajo coordinado con todos los actores involucrados y que a la vez se sienten las bases de la integralidad de los valores de los territorios patrimoniales ligados a una gestión adecuada que se materialice en la mejora de la calidad de vida de sus habitantes. 


\section{BIBLIOGRAFÍA}

- Berg, L. (2005) Restauración de las iglesias de Chiloé, conservando lo infinito: proyecto y obras 1988-2002. Santiago: Editorial Universitaria

- Cañizares Ruiz, M. ${ }^{a}$ C. (2014) Paisajes culturales, Ordenación del Territorio y reflexiones desde la Geografía en España. Polígonos: Revista de Geografía, n. ${ }^{\circ} 26$, pp. 147-180. Disponible en: http://revpubli.unileon.es/ojs/index. php/poligonos/article/view/1703 [Consulta: 27/04/2021]

- Charola, E., Korth, G.M.A, Cedrola, M.L., Magadán, M. L., Kanan, M.I. y Villegas Jaramillo, M.M. (2009) Manual básico de conservación para las misiones jesuíticas guaraníes. Brasil, Argentina, Paraguay y Uruguay. Nueva York: World Monuments Fund (WMF), Unesco. Disponible en: https://www.wmf.org/sites/default/files/article/pdfs/ Jesuit\%20Mission\%20Manual\%20Reduced.pdf [Consulta: 29/04/2021]

- CMN [Consejo de Monumentos Nacionales de Chile] (2021) Monumentos. Disponible en: https://www. monumentos.gob.cl/monumentos [Consulta: 29/04/2021]

- CMN [Consejo de Monumentos Nacionales de Chile] (199) Postulación de las iglesias de Chiloé para su inclusión en la Lista del Patrimonio Mundial de la UNESCO. Cuadernos del Consejo de Monumentos Nacionales. Segunda Serie, n. ${ }^{\circ}$ 29. Disponible en: https://www.uchile. cl/cultura/chiloe/articulos/Postulaciones\%20de\%20las\%20 iglesias\%20de\%20Chiloe.pdf [Consulta: 29/04/2021]

- FAMSV [Fundación Altiplano Monseñor Salas Valdés] (2012) Manual básico de restauración y conservación de construcciones patrimoniales de tierra y piedra de Arica y Parinacota. Santiago de Chile: FAMSV

- FAMSV [Fundación Altiplano Monseñor Salas Valdés] (2018) Pueblos Andinos. Arica y Parinacota. Arica: FAMSV

- Fundación Altiplano (2019) Programa de reforzamiento del modelo de gestión de la Ruta de las Misiones-Saraña. Arica y Parinacota. Cod. BIP: N 30480407-0. Subsecretaría de Desarrollo Regional y Administrativo, Gobierno de Chile; Arica y Parinacota, Gobierno Regional; Consejo Regional de Arica y Parinacota. Disponible en: https://issuu.com/ fundacionaltiplano/docs/reforzamiento_de_modelo_de_ gesti_n_ruta_de_las_mis [Consulta: 11/05/2021]

- Galindo González, J. y Sabaté Bel, J. (2009) El valor estructurante del patrimonio en la transformación del territorio. Apuntes, vol. 22, n. ${ }^{\circ} 1$, pp. 20-33

- Guarda, G. (1984) Iglesias de Chiloé, 1700. Santiago: Editores Universidad Católica de Chile

- Heinsein Planella, C. y Larraín Aninal, F. ( 2017) El espíritu del Paisaje, la Conservación como Estrategia de Desarrollo. En: Arica y Parinacota Paisaje Cultural de América. Santiago de Chile: FAMSV, pp. 277-286
- Ministerio de las Culturas, las Artes y el Patrimonio (2019) Estudio Inventario Iglesias del Archipiélago de Chiloé Pertenecientes a la Escuela Chilota de Arquitectura Religiosa en Madera. Santiago: Subsecretaría del Patrimonio Cultural. Disponible en: https://www.cultura.gob. $\mathrm{cl} /$ publicaciones/estudio-inventario-iglesias-de-la-escuelachilota/ [Consulta: 28/04/2021]

- Montecinos Barrientos, H., Salinas Jaque, I. y Basáez Yau, P. (1995) Las iglesias misionales de Chiloé. Santiago de Chile: Universidad de Chile, Facultad de Arquitectura y Urbanismo

- Moreno R. y Pereira, M. (2011) Arica y Parinacota: la Iglesia en la Ruta de la Plata. Viña del Mar (Chile): Ediciones Altazor

- Novick, A. (2011) Los proyectos territoriales en perspectiva. En: Charrière, M. (dir.) Planes, proyectos e ideas para el AMBA. Buenos Aires: Consejo Profesional de Arquitectura y Urbanismo,pp. 35-47

- Pereira Campos, M.T. (2019) Arte y devoción en la ruta de la plata de Potosi, iglesias Andinas (S. XVII-XIX). Tesis doctoral inédita. Universidad de Sevilla. Disponible en: https://hdl.handle.net/11441/85309 [Consulta: 29/04/2021]

- Rojas, E. y Vivaldi, R. (1979) Chiloé, cultura y bordemar. Chiloé: Ediciones Puertazul

- Sabaté Bel, J. (2010) De la preservación del patrimonio a la ordenación del paisaje: intervenciones en paisajes culturales (Europa-Latinoamérica). Labor e Engenho, vol. 4, n. ${ }^{0} 1$, pp. 10-25. Disponible en: https://periodicos. sbu.unicamp.br/ojs/index.php/labore/article/view/1686 [Consulta: 08/04/2021]

- UNESCO (2021) Lista tentativa de Chile. Disponible en: https://whc.unesco.org/en/tentativelists/state $=\mathrm{cl}$ [Consulta: 29/04/2021]

- Urbina Carrasco, X. (2009) La frontera de arriba en Chile Colonial. Interacción hispano-indígena en el territorio entre Valdivia y Chiloé e imaginario de sus bordes geográficos, 1600-1800. Santiago, Chile: Centro de Investigaciones Diego Barras Arana; Valparaíso, Chile: Pontificia Universidad Católica de Valparaíso 